\title{
The Relative Importance of Northern Overflow and Subpolar Deep Convection for the North Atlantic Thermohaline Circulation
}

\author{
RALF DÖSCHER* AND RENÉ REDLER \\ Institut für Meereskunde, Kiel, Germany \\ (Manuscript received 26 September 1995, in final form 4 February 1997)
}

ABSTRACT

\begin{abstract}
The relative importance of the formation of different North Atlantic Deep Water masses on the meridional overturning is examined with a non-eddy-resolving version of the CME model. In contrast to a frequently held belief, convective deep-water formation south of the North Atlantic sill does not significantly force the largescale overturning if an adequate overflow across the sill can be represented by the model. The sensitivity of the meridional transport to the surface thermohaline forcing is increased under alternate climatic conditions such as increased surface cooling or reduced overflow compared to the present-day situation. The results indicate that climate models may be too sensitive to decadal timescale variability of the surface forcing in subpolar regions.
\end{abstract}

\section{Introduction}

The global conveyor belt connecting the ocean basins is an expression of the thermohaline-driven large-scale meridional circulation. Because of its capacity to transport large amounts of heat and $\mathrm{CO}_{2}$, it plays an important role in the climate system. In the North Atlantic, the surface branch of the conveyor is made up of the warm Gulf Stream and North Atlantic Current in the upper layer. This flow is compensated by a cold southward flow of North Atlantic Deep Water (NADW) within the deep western boundary current (DWBC) (Fine and Molinari 1988; Molinari et al. 1992). Roemmich and Wunsch (1985) find an overturning of $17 \pm 4 \mathrm{~Sv}$ (Sv $\equiv 10^{6} \mathrm{~m}^{3} \mathrm{~s}^{-1}$ ) at $24^{\circ} \mathrm{N}$ using an inverse method on a transatlantic hydrographic section.

Besides convection around Antarctica, the major forcing regions of the conveyor belt are thought to be located in both the northwest subpolar Atlantic and the Nordic seas. The latter gives rise to a southward overflow across the North Atlantic sills (Mauritzen 1994). Tracer studies (e.g., Broecker 1991) show a spreading of convectively formed water masses from the northwestern North Atlantic. The contribution of subpolar deep-water formation (south of the sill) to the large-scale deep-water

* Current affiliation: Alfred Wegener Institut für Polar- und Meeresforschung, Bremerhaven, Germany.

Corresponding author address: Dr. Ralf Döscher, Alfred-WegenerInstitut für Meeres- und Polarforschung, Am Handeshafen 12, 27570 Bremerhaven, Germany.

E-mail: doescher@awi-bremerhaven.de transport has been estimated by quantifying the volume of homogenized water and assuming it to be exported within one year (Clarke and Gascard 1983). Another approach is to estimate the rate of warm-to-cold water transformation (McCartney and Talley 1984; Speer and Tziperman 1992). These indirect methods give transports of between 4 and $9 \mathrm{~Sv}$ in the Labrador Sea, and may have suggested a view of subpolar surface-forced deep-water production as a significant contributor to the deep southward transport. On the other hand, it is not clear whether these transport estimates represent the true dynamic effect of deep convection on the overturning circulation because the newly formed deep water also spreads horizontally. This problem represents a gap in our understanding of deep convection and large-scale overturning. Our main question in this context is: What are the relative contributions of northern overflow water and deep convection in the subpolar North Atlantic (south of the sill) to the meridional overturning in a GCM of the North Atlantic? We address this issue by analyzing a number of model experiments with different forcing configurations.

Several previous model experiments seemingly indicate a distinct sensitivity to the thermal surface boundary condition (e.g., Bryan 1987; Maier-Reimer et al. 1993). Both models were forced at the surface only and did not take into account the forcing from the Nordic seas (north of Iceland). The model of Bryan was restricted to a single idealized basin and thus was completely isolated from lateral forcing by adjacent basins. The global model of Maier-Reimer et al. suffers from a much too weak overflow across the Greenland-Iceland-Scotland ridge and is therefore similarly isolated 
from the Nordic seas. It has not yet been tested whether their results persist in the presence of a realistic northern overflow. Therefore, we systematically vary the forcing at the surface and in the overflow region of our model.

A numerical model of the North Atlantic developed within the framework of the WOCE Community Modelling Effort (CME) enables us to address the question raised above because its water mass exchange with the Nordic seas is parameterized by a restoring adjacent to the northern model boundary, which is a closed wall at $65^{\circ} \mathrm{N}$. Both restoring at the surface and at the northern boundary can easily be varied to set up a series of experiments. In the restoring zone at the northern boundary, temperature and salinity are forced to Levitus (1982) values. This gives rise to a local adjustment of the velocity field to the density structure. Directly at the boundary, the constraint of continuity causes strong vertical velocities. This implies that the North Atlantic part of the conveyor belt is closed artificially within the boundary zone and that this region represents sinking and upwelling in other parts of the global ocean. As an alternative to this restoring technique, truly open boundary conditions with specified inflow and radiating outflow are also employed, reducing the artificial upwelling.

A strong dependence of the meridional overturning on the overflow water mass properties specified by the northern boundary restoring was found in the non-eddyresolving version of the CME model by Döscher et al. (1994). Two experiments illustrate this: restoring to Levitus data [which do not contain any Denmark Strait overflow water (DSOW) due to the smoothing procedures applied] in the Denmark Straits boundary zone gives $17 \mathrm{~Sv}$ overturning, while a more realistic hydrography results in an increased transport of $21 \mathrm{~Sv}$ as well as changes in the structure of the thermohaline circulation. Holland and Bryan (1994) also mention a strong influence of the sidewall boundary zones on the overturning. Gerdes and Köberle (1995) achieve a similar result after introducing a DSOW-like water mass by strong surface density forcing northwest of Iceland in a model of the North Atlantic including the Arctic Ocean. These results suggest a substantial importance of overflow water masses, whereas previous sensitivity studies without northern overflows indicated a distinct sensitivity on surface forcing. Therefore, we are encouraged to attempt a more general examination of the influence of the boundary forcing on the meridional circulation in the CME model. The intention is to clarify the dynamic implications of the forcing by overflow water masses (represented by sidewall boundary conditions) in comparison to the surface forcing.

Our model results show that when restoring to present-day climatology, subpolar convection driven by the surface density flux is of minor importance for the strength of the overturning. This is in contradiction to the $7 \mathrm{~Sv}$ sinking contribution to the conveyor belt proposed by Schmitz and McCartney (1993) for the Lab- rador Sea. Additionally, this work examines under which circumstances surface-forced deep-water formation may affect the meridional circulation in the model. The results illuminate the role of sidewall forcing, representing the overflow from polar regions, in the preconditioning of subpolar deep convection. Further, the results suggest that climate models may be too sensitive: without a North Atlantic overflow the dynamic response to surface forcing variability on decadal timescales may be overestimated.

A brief description of the model and the experiments is given in sections 2 and 3 . Section 4 concentrates on the relation between different forcing components (at the northern boundary and at the surface) and the overturning strength. For details of other features of the CME model concerning either the horizontal or meridional circulation, the reader is referred to other CME publications (e.g., Böning et al. 1996). Section 5 gives a summarizing discussion.

\section{The model}

The numerical model is based on the primitive equations as described by Bryan (1969) and Cox (1984). The specific model configuration was developed by Bryan and Holland (1989) for the WOCE CME project. In the present study, the non-eddy-resolving version of the CME model, which was described by Döscher et al. (1994) is used. The horizontal resolution is $1^{\circ}$ in latitude and $1.2^{\circ}$ in longitude. The model domain represents the Atlantic Ocean between $15^{\circ} \mathrm{S}$ and $65^{\circ} \mathrm{N}$ with realistic bathymetry. The northern and southern boundaries as well as the Straits of Gibraltar are closed. The vertical is discretized with 30 levels; the grid spacing increases smoothly from $35 \mathrm{~m}$ at the surface to $250 \mathrm{~m}$ below $1000-\mathrm{m}$ depth. The maximum depth is $5500 \mathrm{~m}$.

The model employs a vertical diffusivity of $0.3 \times$ $10^{-4} \mathrm{~m}^{2} \mathrm{~s}^{-1}$ and a vertical viscosity of $10^{-3} \mathrm{~m}^{2} \mathrm{~s}^{-1}$. A Laplacian lateral friction and isopycnal diffusion is applied to parameterize the mixing effect of mesoscale eddies (Redi 1982; Cox 1987). The coefficients for along isopycnal diffusivity are depth-dependent and vary between $2 \times 10^{3} \mathrm{~m}^{2} \mathrm{~s}^{-1}$ at the surface and $0.5 \times$ $10^{3} \mathrm{~m}^{2} \mathrm{~s}^{-1}$ at greater depths with an $e$-folding depth scale of $500 \mathrm{~m}$. A background lateral diffusivity $\left(10^{2}\right.$ $\left.\mathrm{m}^{2} \mathrm{~s}^{-1}\right)$ is necessary to prevent numerical noise. A constant eddy coefficient is used for the horizontal viscosity $\left(10^{4} \mathrm{~m}^{2} \mathrm{~s}^{-1}\right)$.

The wind forcing is given by the climatological monthly mean wind stresses of Isemer and Hasse (1987). The thermohaline circulation is driven by a relaxation of temperature and salinity at the surface and adjacent to the northern and southern boundaries. The surface salinity is restored to the monthly mean values of Levitus (1982) with a restoring time of 25 days, short enough to follow the seasonal cycle. The surface temperature is relaxed to monthly values of "apparent" atmospheric temperature $T^{*}$ as described by Han (1984). 
That heat flux formulation implicitly includes effects of direct solar shortwave radiation, longwave back-radiation, latent and sensible fluxes. A surface mixed layer model of Kraus-Turner type, driven by the wind work is included as a purely vertical process.

The standard version of the $1^{\circ} \mathrm{CME}$ model-named $\mathrm{C} 1$-is described first. It is identical to the experiment C1 of Döscher et al. (1994). Because of the restricted model domain, zonal strips of $4^{\circ}$ lat are used as restoring zones at the northern and southern boundary in a similar manner as in the models of Sarmiento (1986) and Semtner and Chervin (1992). The restoring timescale in these buffer zones varies from 6.25 days in the first active grid cell adjacent to the boundary to $8.33,12.5$, and 25 days in the fourth grid cell away from the boundary. Within these boundary zones potential temperature and salinity are restored to prescribed climatological monthly means from the atlas of Levitus (1982). This boundary restoring represents the influence of diapycnic processes taking place outside the model domain, that is, production of the source waters for NADW in the Nordic seas and upwelling of NADW in the global ocean. It is thus assumed that outside processes supply the model with interannually unvarying water mass properties as given by the Levitus data. Neglecting in this way the interaction between the water masses in the model domain and outside it exerts a stabilizing effect on the model's circulation. In addition to the two main boundary zones, there are two smaller restoring zones. One on the Labrador shelf prevents the model from producing unrealistically low temperatures due to intense wintertime cooling in the absence of an ice model. Off Gibraltar, a second restoring zone represents the influence of the Mediterranean Sea.

As an alternative to the restoring lateral boundary conditions, truly open boundary conditions are used in two experiments (O1 and O1-1). We adopt a different approach for the northern and southern boundary. Following Stevens (1991), the barotropic streamfunction is computed along the southern boundary from the Sverdrup equation with monthly varying wind stress data. The integration of the Sverdrup relation is done starting at the coast of Africa. A boundary current of $500 \mathrm{~km}$ width is defined off the coast of South America to balance the Sverdrup transport. Since the Sverdrup relation cannot be assumed to be a good approximation of barotropic transports in higher latitudes (Bryan et al. 1995), a different procedure is necessary at the northern boundary $\left(65^{\circ} \mathrm{N}\right)$. The transport into the Atlantic between Greenland and Iceland is estimated to be $5.6 \mathrm{~Sv}$, and is kept constant in time. This is balanced by an equal and opposite outflow through the Iceland-Norway section. Baroclinic current profiles at the open boundaries are computed from the linearized momentum equation and can adjust freely to the local density gradients. Heat and salt are advected out of the model at each outflow point. Inflowing water is characterized by Levitus temperatures and salinities.
TABLE 1. Experiment combinations of different forcing at the northern boundary and at the surface.

\begin{tabular}{|c|c|c|c|c|c|c|}
\hline & \multirow[b]{2}{*}{$\begin{array}{l}\text { Northern } \\
\text { boundary }\end{array}$} & \multicolumn{5}{|c|}{ Surface } \\
\hline & & $\begin{array}{l}\text { Basic } \\
\text { Sur- } \\
\text { face } \\
\text { re- } \\
\text { storing } \\
\text { to } T^{*} \text {, } \\
\quad S\end{array}$ & $\begin{array}{l}\text { No } \\
\text { surface } \\
\text { forcing }\end{array}$ & $\begin{array}{c}-2 \\
\text { Surface } \\
\text { restoring } \\
\text { to } T^{*}, S \\
\text { only } \\
\text { between } \\
15^{\circ} \mathrm{S} \text { and } \\
49^{\circ} \mathrm{N}\end{array}$ & $\begin{array}{c}-3 \\
\text { Negative } \\
\text { fresh- } \\
\text { water } \\
\text { anomaly } \\
\text { in the } \\
\text { Labrador } \\
\text { Sea }\end{array}$ & $\begin{array}{c}-4 \\
\text { Surface } \\
\text { restoring } \\
\text { to } T^{*} \\
-3.5^{\circ} \mathrm{C} \\
\text { between } \\
48^{\circ} \mathrm{N} \text { and } \\
61^{\circ} \mathrm{N}\end{array}$ \\
\hline $\mathrm{C} 1$ & $\begin{array}{l}\text { Levitus at lateral boundaries } \\
15^{\circ}-11^{\circ} \mathrm{S}, 61^{\circ}-65^{\circ} \mathrm{N} \\
\text { timescale }=\text { std. }\end{array}$ & $\mathrm{C} 1$ & $\mathrm{C} 1-1$ & C1-2 & C1-3 & C1-4 \\
\hline $\mathrm{C} 2$ & $\begin{array}{l}\text { DSOW from single section in } \\
\text { northern boundary zone }\end{array}$ & ${ }^{n} \mathrm{C} 2$ & & & & C2-4 \\
\hline $\mathrm{C} 3$ & $\begin{array}{l}\text { Weak DSOW in northern boundary } \\
\text { zone }\end{array}$ & y $\mathrm{C} 3$ & & & & C3-4 \\
\hline $\mathrm{C} 4$ & $\begin{array}{l}\text { Restoring to Levitus in a small } \\
\text { northern boundary zone } \\
\text { timescale }=0.25^{*} \text { std. }\end{array}$ & $\mathrm{C} 4$ & C4-1 & & & \\
\hline $\mathrm{C} 0$ & $\begin{array}{l}\text { No restoring in the northern } \\
\text { boundary zone }\end{array}$ & $\mathrm{CO}$ & $\mathrm{C} 0-1$ & & & \\
\hline $\mathrm{O} 1$ & Open boundaries & $\mathrm{O} 1$ & O1-1 & & & \\
\hline
\end{tabular}

\section{Experiments}

The model has been integrated for 50 years in the configuration of the reference case $\mathrm{C} 1$, starting from the Levitus January conditions for temperature and salinity to achieve a dynamic quasi-equilibrium state. This serves as an initial condition for a host of sensitivity experiments listed in Table 1, differing by the thermohaline forcing that is applied at the surface and lateral boundaries. In particular, the impact of surface forcing on the meridional overturning is investigated in the first set of experiments (group C1). The surface thermohaline forcing is completely switched off in case C1-1, while it is active only south of $49^{\circ} \mathrm{N}$ in case C1-2. To simulate the impact of an idealized "great salinity anomaly" (Lazier 1980), a negative salinity anomaly of 0.7 psu was added to the haline surface forcing in experiment C1-3. Enhanced forcing due to atmospheric cooling over the subpolar gyre is achieved in C1-4 by decreasing the apparent temperature by $3.5^{\circ} \mathrm{C}$ between $48^{\circ} \mathrm{N}$ and $61^{\circ} \mathrm{N}$.

Selected experiments of the $\mathrm{C} 1$ group are then repeated with now different forcing mechanisms at the lateral boundaries. The importance of the northern boundary restoring condition is the subject of all the remaining experiments in groups $\mathrm{C} 2, \mathrm{C} 3, \mathrm{C} 4, \mathrm{C} 0$, and $\mathrm{O} 1$. As a first step, the northern boundary restoring is switched off completely in experiment $\mathrm{C} 0$ (and in $\mathrm{C} 0-1$, the surface forcing is additionally disabled). In $\mathrm{C} 2$, a restoring boundary condition with an idealized cold DSOW feature based on an observed section is prescribed at the boundary east of Greenland. This experiment is described in detail by Döscher et al. (1994). Case C3 is similar to C2, but the cold DSOW is concentrated closer to the eastern continental slope of Greenland. The volume of water with $T<3^{\circ} \mathrm{C}$ is reduced by $40 \%$ in C3 compared to C2. Experiments C2 and $\mathrm{C} 3$ are also repeated with the enhanced atmospheric cooling (runs C2-4 and C3-4). 
The $\mathrm{C} 4$ and $\mathrm{O} 1$ sets of experiments are aimed at testing the influence of the specific geometry of the northern boundary condition. In $\mathrm{C} 4$, the width of the northern restoring zone is reduced from four to two zonal slabs $\left(2^{\circ}\right)$, and the restoring timescale is decreased. The same geometry is used in C4-1, but the surface buoyancy fluxes in the Atlantic are disabled in addition. Two experiments with truly open boundary conditions instead of restoring are performed: O1, corresponding to the standard experiment $\mathrm{C} 1$, and $\mathrm{O} 1-1$ without surface thermohaline forcing. In these experiments, the velocity field is initially set to zero. Following Böning et al. (1995), the horizontal viscosity in O1 and O1-1 is doubled to $2 \times 10^{4} \mathrm{~m}^{2} \mathrm{~s}^{-1}$ in order to reduce artificial upwelling inshore of the western boundary. The same temperature and salinity fields at the surface as for the experiments in group $\mathrm{C} 1$ are used, as described in section 2. At inflow points along the open boundaries at $65^{\circ} \mathrm{N}$ (keeping the Davis Strait closed) and $15^{\circ} \mathrm{S}$, the model is forced toward Levitus temperatures and salinities. Except for close to the boundaries, the circulation in the open boundary experiments remains the same as in the corresponding experiments with closed boundaries.

\section{Results}

The thermohaline circulation of the model is represented by the streamfunction of the zonally integrated meridional volume transport ("meridional overturning," Fig. 1a).

The pattern for experiment $\mathrm{C} 1$ is shown in Fig. 1a: five major cells are seen. The main cell centered at depth between 1000 and $2000 \mathrm{~m}$ extends over the whole model domain. The maximum transport of $17 \mathrm{~Sv}$ is at $44^{\circ} \mathrm{N}$. The upper northward-flowing branch is mainly formed by upper-ocean western boundary currents (North Brazil Current, Antilles Current, Florida Current, Gulf Stream) and the North Atlantic Current. The lower southward flowing branch shows the flow of NADW originating in the northern boundary zone and in subpolar latitudes. The transport is concentrated in the western part of the deep North Atlantic. Below the main cell there is a northward flow of Antarctic Bottom Water (AABW), which feeds the southward NADW transport in the north (AABW-cell). Superimposed upon the upper northward flow are three shallow wind-driven cells. This annual mean circulation pattern is nearly constant, following an initial decadal-timescale dynamic adjustment from the initial conditions. The subsequent experiments are integrated to a new dynamic quasi-equilibrium, which is reached within 10-15 years after a switch in boundary conditions. The maximum transport of the main overturning cell at $44^{\circ} \mathrm{N}$ (the overturning strength), serves as a monitoring quantity of the relative influence of the different forcing components that are tested, as illustrated in Fig. 2a.

The thermohaline circulation cannot be linearly de-
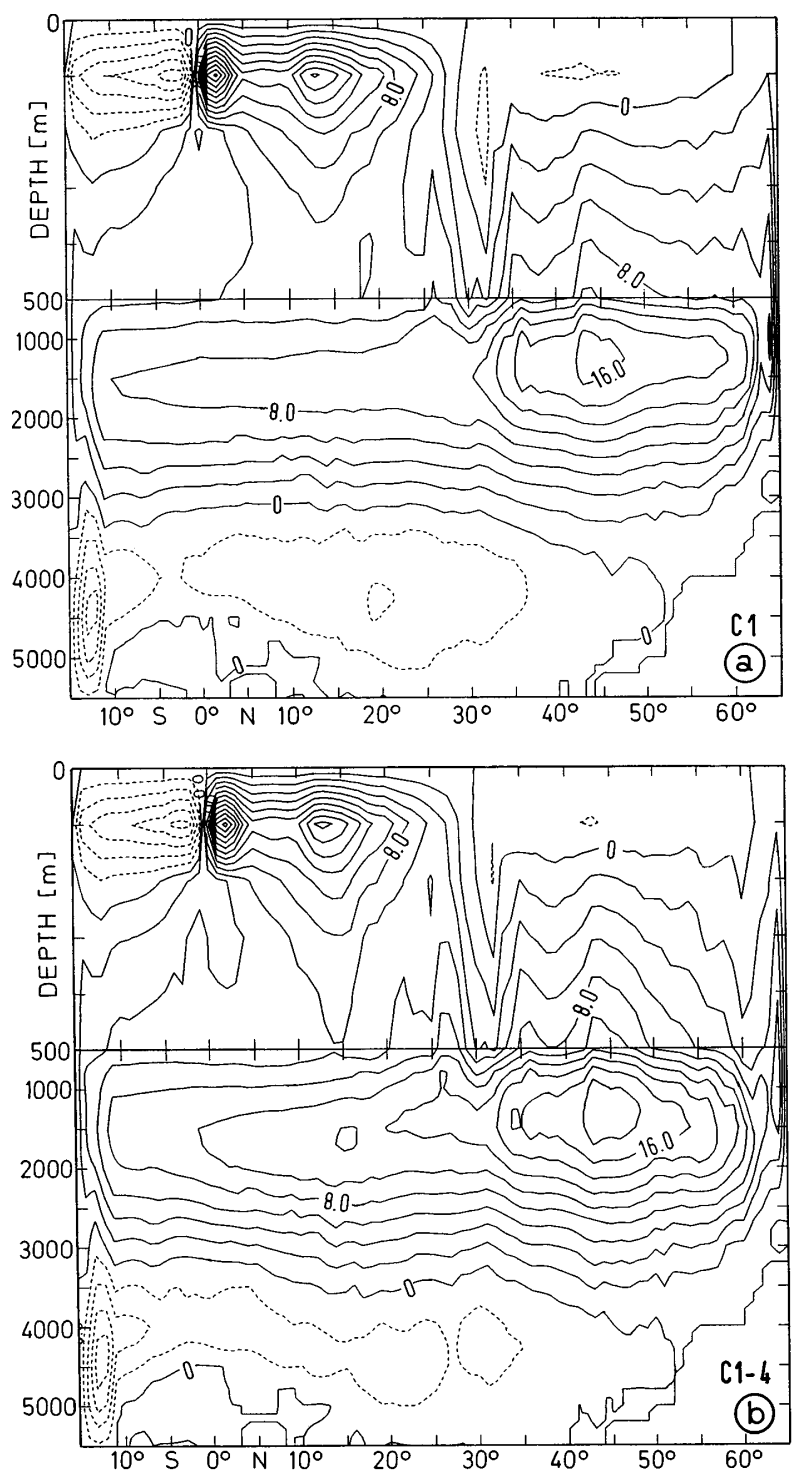

FIG. 1. Streamfunction of the zonally integrated volume transport in the meridional-vertical plane: averages over the final year of (a) the standard experiment $\mathrm{C} 1$ and (b) C1-4; contour interval is $2 \mathrm{~Sv}$.

scribed as a function of the thermohaline forcing. The total circulation is a result of the nonlinear interaction between the circulation itself and the tracer flux within the restoring zones. It is not given by the sum of the circulations driven by single forcing components. For example, the overturning and vertical transports in the standard experiment $\mathrm{C} 1$ are dominated by the boundary zones as demonstrated by case C1-1 (Fig. 2a): without surface forcing the overturning is reduced by only $1 \mathrm{~Sv}$. On the other hand, the vertical transport north of $44^{\circ} \mathrm{N}$ does not disappear if only the northern boundary is deactivated. The sinking branch is then reduced from 17 $\mathrm{Sv}$ in $\mathrm{C} 1$ to $11.3 \mathrm{~Sv}$ in $\mathrm{C} 0$. In this case, the thermohaline surface forcing becomes the main driving force of the meridional overturning. However, the influence of the 



FIG. 2. Maximum of the zonally integrated volume transport streamfunction in the depth range of the major deep cell at $44^{\circ} \mathrm{N}$ as a function of time.

southern boundary zone obviously is of secondary order, because turning off the surface forcing as well as the northern boundary $(\mathrm{C} 0-1)$ results in a nearly complete breakdown of the main overturning cell. Thus, with active northern sidewall forcing, the surface forcing plays only a minor role in driving the overturning.

The sensitivity of these results is tested against the specification of the restoring zones. Consistent with the results above, the overturning strength of two pairs of sensitivity runs (in Figs. $2 \mathrm{a}$ and $2 \mathrm{~b}$ ) show only weak differences between the cases with and without surface forcing. In $\mathrm{C} 4$, the volume of the northern boundary zone is reduced to two zonal slabs while the restoring time is decreased by a factor 4 . This configuration gives an overturning of about $15.4 \mathrm{~Sv}$. When the thermohaline surface forcing is skipped (C4-1), the overturning again decreases only a little to $14.3 \mathrm{~Sv}$. The results of the restoring boundary runs can be further confirmed by using truly open boundary conditions $(\mathrm{O} 1, \mathrm{O} 1-1)$. The overturning of the open boundary standard case $\mathrm{O} 1$ is
15.43 Sv [less than that in $\mathrm{C} 1$; this indicates the reduced efficiency of the lateral forcing and the effect of the doubled horizontal viscosity $\left.\left(2 \times 10^{4} \mathrm{~m}^{2} \mathrm{~s}^{-1}\right)\right]$. This transport decreases only slightly to $15.0 \mathrm{~Sv}$, if the surface forcing is skipped in the case O1-1. Thus, the dominance of the overflow water masses appears to be robust against the specific design of the boundary condition. Similar overturning strengths can be produced in all three cases: with restoring in two different configurations or with truly open boundary conditions.

The results of the experiments are summarized and illuminated by relating the overturning strength to the mean densities in selected forcing regions. Two regions are considered: a strip just south of the northern boundary zone $\left(48^{\circ}-61^{\circ} \mathrm{N}\right.$, above $\left.1500 \mathrm{~m}\right)$ and the deeper part of the northern boundary zone in the area of the Denmark Strait $\left(47^{\circ}-17^{\circ} \mathrm{W}\right.$, below $\left.1250 \mathrm{~m}\right)$. These regions are chosen in a way that the main water masses suitable for driving the thermohaline circulation are represented. The first region encloses the area of free deep convection outside the boundary zone (henceforth the averaging area for "subpolar density") and the second covers the densest overflow water masses of the northern boundary zone ("northern density").

Figure 3 shows the relation between the "subpolar density," the "northern density," and the maximum overturning, which is contoured. All experiments whose boundary zone geometry does not differ from the standard are included in the diagram. Only a few experiments $(\mathrm{C} 1, \mathrm{C} 1-3, \mathrm{C} 2, \mathrm{C} 3)$ can be regarded as realistic in the sense of being forced with climatological Levitus data and some improvements described in section 3 . Clearly, the limited number of data points (11) allows us to show qualitative model behavior only; however, the compilation gives us an impression of the dynamic consequences of different types of forcing.

For high northern densities (in the upper part of Fig. 3) an increase of the subpolar density is associated with a very weak increase of overturning transport, as represented by the transition from $\mathrm{C} 3$ to $\mathrm{C} 3-4$ and from $\mathrm{C} 2$ to $\mathrm{C} 2-4$ due to enhanced surface cooling. As the northern density is reduced, the dependence of the transport on the subpolar density increases. For high subpolar densities, a strengthening of the surface forcing from C1-1 (to $\mathrm{C} 1-2, \mathrm{C} 1-3, \mathrm{C} 1$ ) to $\mathrm{C} 1-4$ leads to a distinct transport increase. This effect gets stronger with further decreasing northern density (the lower part of the diagram) and increasing subpolar density (right-hand side).

Figure 3 also makes the existence of two regimes evident:

- For high "northern densities" and low "subpolar densities" (upper-left corner), changes of surface forcing do not affect the overturning.

- For other combinations of both densities, changes of surface forcing have dynamic consequences that increase with increasing subpolar density (i.e., deviation 


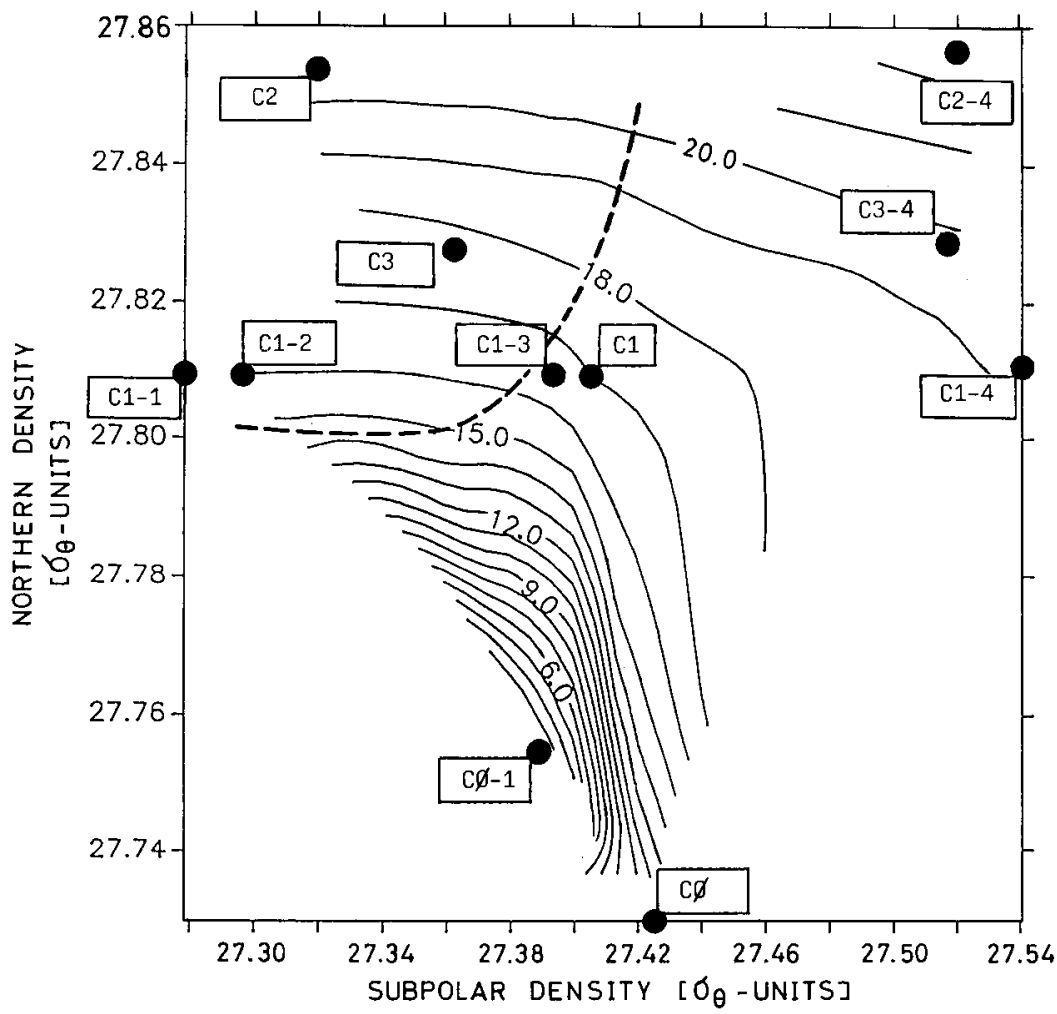

FIG. 3. Overturning $(\mathrm{Sv})$ against mean potential densities $\left(\sigma_{\Theta}\right)$. Ordinate: the "northern density" in the lower part of the boundary zone in the region of the Denmark Strait $\left(47^{\circ} \mathrm{W}\right.$ $-17^{\circ} \mathrm{W}$ below $1250 \mathrm{~m}$ ). Abscissa: the "subpolar density" in a $13^{\circ}$ wide zonal strip south of the northern boundary zone $\left(48^{\circ} \mathrm{N}-61^{\circ} \mathrm{N}\right.$, above $\left.1500 \mathrm{~m}\right)$. Two regimes are separated by the dashed line: dynamically nonrelevant surface forcing in the upper-left corner and relevant surface forcing in the remaining parts of the diagram.

from Levitus surface forcing) and decreasing northern density.

The transition zone between the two regimes is diffuse. Thus, the dashed line dividing these two regimes should be understood as a rough indication of its position.

These coarse resolution experiments give the surprising result that under certain conditions, near to the present-day climate case (expt C1), thermohaline surface forcing in the North Atlantic is not important for the overturning circulation. A complete deactivation of that driving (expt C1-1) gives only a small reduction of about $1 \mathrm{~Sv}$, although convective deep water formation south of the boundary zone is suppressed (not shown). This is in contradiction to the frequently held belief in the importance of convective deep-water formation in the northern North Atlantic. In the description of Schmitz and McCartney (1993), 7 Sv of Labrador Sea Water (LSW) sink down and contribute directly to the deep western boundary transport. According to this scheme, a cessation of deep convection should result in a significant reduction of the overturning. This cannot be confirmed with our experiments for present-day conditions. Stronger surface forcing, however, leads to a different scenario: a changed overturning circulation (i.e., a changed vertical gradient of the meridional transport) is related to the mean zonal density gradient by the thermal wind equation. Therefore, in the case of our experiments different dynamic effects of surface forcing must be associated with corresponding abilities to influence the mean zonal density gradient in the depth range of the NADW.

The depth of homogenization after a convection event depends on the preconditioning. A cyclonic circulation and a weak stratification both promote deep convection (Killworth 1983). Water masses originating in the Denmark Strait are exported via the East Greenland Current and a deep western boundary current into the northwestern subpolar region, where they cause a stratification that in the standard case $\mathrm{C} 1$ does not allow increases of the mean zonal density gradient due to convection and hence little ability to enhance the overturning transport.

The deepest homogenization by free deep convection occurs in the case of strong northern surface forcing (C1-4). This leads to a distinctly increased mean zonal density gradient compared to the standard case $\mathrm{C} 1$. Figure 4 demonstrates this effect at $54^{\circ} \mathrm{N}$ : the zonal density gradient shows strongest differences above $1800 \mathrm{~m}$ and 


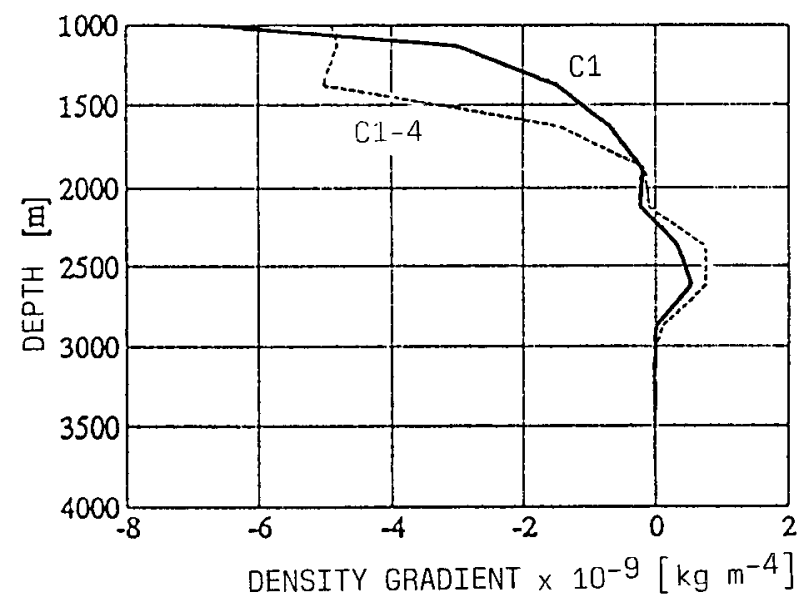

FIG. 4. Profile of the zonally averaged potentially density gradient (in $\mathrm{kg} \mathrm{m}^{-2}$ ) for the cases $\mathrm{C} 1$ and $\mathrm{C} 1-4$ at $54^{\circ} \mathrm{N}$.

a weaker effect below. At $60^{\circ} \mathrm{N}$ near the northern boundary zone (not shown), this effect is much weaker. The resulting change in horizontal transport divergence must be compensated by an increased vertical transport between $54^{\circ} \mathrm{N}$ and $60^{\circ} \mathrm{N}$. The corresponding overturning pattern is shown in Fig. 1b.

If the surface forcing has the ability to produce a distinctly increased zonal density gradient, this leads to a corresponding strong sinking in the region of deep convection. This picture of a dynamically important surface forcing in the case C1-4 is in better agreement with frequently held beliefs, but it cannot be achieved in the model when present-day climatological data is used in the forcing.

\section{Summary and discussion}

The dependence of the meridional overturning circulation on different thermohaline forcing regions has been examined using a non-eddy-resolving version of the CME North Atlantic model. This work suggests an uncommon view of the role of subpolar deep-water formation south of the North Atlantic sills: it appears to be much less important than suggested by several other sensitivity studies (Bryan 1987; Maier-Reimer et al. 1993) and by observationally deduced pictures (sketched by Schmitz and McCartney 1993).

Using climatological temperatures and salinities for both the surface restoring and lateral boundary conditions (either restoring in boundary zones as in the standard experiment $\mathrm{C} 1$ or truly open boundary conditions as in O1), the combined northern and southern boundary forcing determine the meridional overturning, while the surface forcing is nearly negligible. Thus, the assumption of sinking and drain-off of newly formed deep water originating in the northern North Atlantic via the deep western boundary current (suggested by, e.g., McCartney and Talley 1984) cannot be confirmed with the CME model. Although deep convection determines $T / S$ char- acteristics in the subpolar North Atlantic, strong vertical transports are located elsewhere.

An inspection of several experiments with restoring zones at lateral boundaries shows two different regimes for the controlling influence on the meridional circulation. In the case of either high densities in the overflow regions at the northern boundary or low densities in the upper subpolar ocean, the overturning is dominated by the boundary zone forcing. Surface forcing has a negligible effect and sinking is concentrated near the northern wall. The second regime is given by the remaining density combinations with smaller density differences. It is characterized by a non-negligible contribution of the surface forcing to the meridional overturning. Under such conditions the water column can become unstable over a wide depth range, and deep convection can distinctly change the mean zonal density gradient in the deep water at the latitude of convection and thus enhance local sinking due to continuity. This second regime can be achieved either by reducing the effectiveness of the boundary forcing (reducing the restoring flux either by increasing the restoring time or decreasing the restoring temperature) or by increasing the surface forcing, but in both cases by amounts that are unrealistically strong for the present-day climate as represented by the Levitus atlas. The standard experiment $\mathrm{C} 1$ with forcing data from present-day climatological observations is situated within a broad transition zone between the regimes. It is only weakly sensitive to negative disturbances of the surface forcing (e.g., a negative surface salinity anomaly in experiment C1-3). These results indicate the dominance of the North Atlantic overflow water masses for the overturning and thus the importance of dense water formation in the Nordic seas under today's climatic conditions.

Implications for the real ocean are hard to estimate because the observational picture of overturning and sinking in the subpolar North Atlantic has not yet been quantified with sufficient accuracy. Therefore, it is not clear whether the standard experiment $\mathrm{C} 1$ gives a good representation of these processes. On the other hand, the model's reliability is strengthened by its insensitivity to the design configuration of the boundary condition: the small relative importance of the surface forcing is reproduced when using smaller restoring boundary zones ( $\mathrm{C} 4$ and $\mathrm{C} 4-1)$ as well as when introducing truly open boundary conditions (O1 and O1-1). Our findings also match with the small sinking in the northwestern North Atlantic of both the eddy-resolving and coarse resolution versions of the CME model described by Böning et al. (1996). This suggests that the reason for the weak effect of surface forcing is the ineffective drainage of convectively formed deep water originating in the subpolar North Atlantic. Better drainage is provided by the boundary currents, which are reached by enlarged convection in our cases C1-4 and C3-4.

The weak effect of negative surface salinity anomalies in the experiments with present-day climatological 
forcing seemingly contradicts other model experiments. A model experiment of Maier-Reimer and Mikolajewicz (1989) with a freshwater inflow of $0.011 \mathrm{~Sv}$ by the St. Lawrence river to the North Atlantic shows a complete shutdown of the surface-driven overturning. The deep-water formation of that model is located completely south of the North Atlantic sills. Thus, the freshwater anomaly acts on all deep-water sources. Possibly, this is also the reason for overturning fluctuations in the coupled model of Delworth et al. (1993): decadal overturning fluctuations appear to be driven by density anomalies in the northern sinking region, where sinking is restricted to the area between $55^{\circ} \mathrm{N}$ and $71^{\circ} \mathrm{N}$. Other ocean models with restoring boundary conditions at the surface but without lateral boundary forcing also show sensitivity of the overturning to variations of the thermal boundary condition at the surface on a longer timescale (Cox and Bryan 1984; Bryan 1987; Maier-Reimer et al. 1993). All these models do not have an overflow in the Denmark Strait because either they do not include topography (Bryan 1987) or they fail to produce an adequate overflow. In the CME model, only the surfacedriven part of the deep-water sources are affected by surface anomalies. Hence the response cannot be as strong. The experiment of Maier-Reimer and Mikolajewicz (1989) very roughly corresponds to the CME case $\mathrm{C} 0-1$ (no northern restoring, no surface forcing), which also shows a shutdown of meridional transport. The role of the Denmark Strait water masses in preconditioning the water column for subpolar deep-water formation is underestimated in these cases.

Our findings are of significance for many circulation models that include the North Atlantic but do not adequately represent the North Atlantic overflow. In this situation, our results suggest that the large-scale thermohaline circulation is unrealistically sensitive on decadal timescales to time-varying surface fluxes in the North Atlantic. The existence of decadal fluctuations of the North Atlantic circulation has been clearly deduced from ice and sediment cores (GRIP 1993; Dansgard et al. 1989). Decadal variability also appears in global climate models but is possibly overestimated in the light of our finding: without a sufficient coupling of Nordic seas and North Atlantic, the response of the ocean to subpolar atmospheric variability may be too strong. On the other hand, in a climate case with reduced production of overflow water in the Nordic seas (north of the North Atlantic sill) with consequently decreased overflow, the overturning would be more sensitive to surface thermohaline forcing in the northern Atlantic than under present-day conditions.

The reliability of climate experiments aimed at discovering the effect of surface forcing anomalies can be strongly improved if the different contributions to the deep-water formation (from south and north of the North Atlantic sill) are taken into account. The steplike representation of topography in geopotential coordinate models suppresses the spreading of overflow water masses from the sill along their isopycnals. Instead, tracer transport in an overflow situation is accompanied by strong vertical mixing and a loss of water mass properties (Beckmann and Döscher 1997). Therefore, a better representation or parameterization of near-bottom flows over sloping topography is necessary for coarse resolution or climate models. The uncertainty about the situation in the real North Atlantic further shows the need for better transport and density observations to enable model verification.

Acknowledgments. We are grateful to A. Beckmann, C. W. Böning, R. Gerdes, and S. Rahmstorf for many discussions. We also thank T. Hughes for helpful comments. This study is supported by the Deutsche Forschungsgemeinschaft, Sonderforschungsbereich 133.

\section{REFERENCES}

Beckmann, A., and R. Döscher, 1997: A method for improved representation of dense water spreading over topography in geopotential-coordinate models. J. Phys. Oceanogr. 27, 581-591.

Böning, C. W., W. R. Holland, F. O. Bryan, G. Danabasoglu, and J. C. McWilliams, 1995: An overlooked problem in model simulations of the thermohaline circulation and heat transport in the Atlantic Ocean. J. Climate, 8, 79-89.

, F. O. Bryan, W. R. Holland, and R. Döscher, 1996: Deep-water formation and meridional overturning in a high-resolution model of the North Atlantic. J. Phys. Oceanogr., 26, 1142-1164.

Broeker, W. G., 1991: The great ocean conveyor. Oceanography, 4, 79-85.

Bryan, F., 1987: Parameter sensitivity of primitive equation ocean general circulation models. J. Phys. Oceangr., 17, 970-985.

, and W. R. Holland, 1989: A high resolution simulation of the wind and thermohaline-driven circulation in the North Atlantic Ocean. Parameterization of Small-Scale Processes, Proceedings Aha Huliko'a Hawaiian Winter Workshop, P. Müller and D. Anderson, Eds., University of Hawaii at Manoa, 99-115.

— C. W. Böning, and W. R. Holland, 1995: On the midlatitude circulation in a high-resolution model of the North Atlantic. $J$. Phys. Oceangr., 25, 289-305.

Bryan, K., 1969: A numerical method for the study of the circulation of the world ocean. J. Comput. Phys., 4, 347-376.

Clarke, R. A., and J.-C. Gascard, 1983: The formation of Labrador Sea Water. Part I: Large-scale processes. J. Phys. Oceanogr., 13, 1764-1778.

Cox, M. D., 1984: A primitive equation, 3-dimensional model of the ocean. Ocean Group Tech. Rep. 1.

- 1987: Isopycnal diffusion in a z-coordinate ocean model. Ocean Modelling (unpublished manuscript), 74, 1-5.

- , and K. Bryan, 1984: A numerical study of the ventilated thermocline. J. Phys. Oceanogr., 14, 674-687.

Dansgard, W., J. W. C. White, and S. J. Johnsen, 1989: The abrupt termination of the Younger Dryas climate event. Nature, 339, 532-533.

Delworth, T., S. Manabe, and R. J. Stouffer, 1993: Interdecadal variations of the thermohaline circulation in a coupled ocean-atmosphere model. J. Climate, 6, 1993-2011.

Döscher, R., C. W. Böning, and P. Herrmann, 1994: Response of circulation and heat transport in the North Atlantic to changes in thermohaline forcing in northern latitudes: A model study. $J$. Phys. Oceanogr., 24, 2306-2320.

Fine, R. A., and R. L. Molinari, 1988: A continuous deep western boundary current between Abaco $\left(26.5^{\circ} \mathrm{N}\right)$ and $\operatorname{Barbados}\left(13^{\circ} \mathrm{N}\right)$. Deep-Sea Res., 35, 1441-1450.

Gerdes, R., and C. Köberle, 1995: On the influence of DSOW in a 
numerical model of the North Atlantic general circulation. $J$. Phys. Oceanogr., 25, 2624-2642.

GRIP, 1993: Climate instability during the last interglacial period recorded in the GRIP ice core. Nature, 364, 203-207.

Han, Y.-J., 1984: A numerical World Ocean General Circulation Model. Part II: A baroclinic experiment. Dyn. Atmos. Oceans, 8, 141172

Holland, W. R., and F. O. Bryan, 1993: Sensitivity studies on the role of the ocean in climate change. Ocean Processes in Climate Dynamics: Global and Mediterranean Examples, P. MalanotteRizzoli and A. R. Robinson, Eds., NATO ASI Proceedings, Kluwer, 111-134.

Isemer, H. J., and L. Hasse: 1987: The Bunker Climate Atlas of the North Atlantic Ocean. Vol. 2, Air-Sea Interactions, SpringerVerlag, $256 \mathrm{pp}$.

Killworth, P. D., 1983: Deep convection in the world ocean. Rev. Geophys., 21, 1-26

Lazier, J. R. N., 1980: Oceanographic conditions at OWS Bravo 1964-1986. Atmos.-Ocean, 18(3), 227-238.

Levitus, S., 1982: Climatological Atlas of the World Ocean. NOAA Prof. Paper No. 13, U.S. Govt. Printing Office, 173 pp.

Maier-Reimer, E., and U. Mikolajewicz, 1989: Experiments with an OGCM on the cause of the Younger Dryas. Max-Planck Institut füf Meteorologie Rep. 39, $13 \mathrm{pp}$

,$--\ldots$, and K. Hasselmann, 1993: Mean circulation of the Hamburg LSG OGCM and its sensitivity to the thermohaline surface forcing. J. Phys. Oceanogr., 23, 731-757.

Mauritzen, C., 1994: A study of the large scale circulation and water mass formation in the Nordic Seas and Arctic Ocean. Ph.D dissertation, Joint Program in Oceanography, Massachussetts Institute of Technology and Woods Hole Oceanographic Institution, $212 \mathrm{pp}$. [Available from Woods Hole Oceanographic Institution, Woods Hole, MA 02543.]

McCartney, M. S., and L. D. Talley, 1984: Warm-to-cold water conversion in the northern Atlantic Ocean. J. Phys. Oceanogr., 14, 922-935.

Molinari, R. L., R. A. Fine, and E. Johns, 1992: The deep western boundary current in the western tropical North Atlantic Ocean. Deep-Sea Res., 39(11/12), 1967-1984.

Redi, M. H., 1982: Oceanic isopynal mixing by coordinate rotation. J. Phys. Oceanogr., 12, 1154-1158.

Roemmich, D., and C. Wunsch, 1985: Two transatlantic sections: Meridional circulation and heat flux in the subtropical North Atlantic Ocean. Deep-Sea Res., 32, 619-664.

Sarmiento, J. L., 1986: On the North and tropical Atlantic heat balance. J. Geophys. Res., 91, 11 677-11 689.

Schmitz, W. J., and M. S. McCartney, 1993: On the North Atlantic circulation. Rev. Geophys., 31, 29-49.

Semtner, A. J., and R. M. Chervin, 1992: Ocean general circulation from a global eddy-resolving model. J. Geophys. Res., 97, 54935550 .

Speer, K., and E. Tzipermann, 1992: Rates of water mass formation in the North Atlantic Ocean. J. Phys. Oceanogr., 22, 93-104.

Stevens, D. P., 1991: The open boundary condition in the United Kingdom Fine Resolution Antarctic Model. J. Phys. Oceanogr., 21, 1494-1499. 